\title{
Academic referencing - a dying art
}

\section{Roger W. Byard ${ }^{1}$ (I)}

Accepted: 20 July 2020 / Published online: 1 August 2020

(C) Springer Science+Business Media, LLC, part of Springer Nature 2020
"It is of course very simple to irritate editors into apoPD Home 1988 [1]

The paper written by Home over three decades ago should become required reading for authors submitting papers to contemporary journals. All of the behaviors and errors that he outlined, somewhat tongue in cheek, in the 1980's continue to manifest themselves in submitted papers today, and often in revisions of these papers. One of the particular banes of editors' lives is the paper that does not have references that are correctly cited in the format specified by the journal.

A question to ask is whether it really matters whether references are consistently and correctly cited in the style demanded by the journal. I personally think that it does. Just as we have uniformity in font size and style in the body of the text, it should be the same for the references. It really does not take much more effort to ensure that the references are correct. In addition, if the references are incomplete or inaccurate readers may not be able to find original sources and so will have to undertake their own time-consuming literature searches, something that would not be required if all had been cited properly in the first place. Academic publishing and study is difficult enough in a time-poor world $[2,3]$ without having to spend time on activities that should not be required.

Unfortunately lack of attention to detail in the references may also be part of a more systemic sloppiness that might also be a factor in the body of the work. This is akin to a type of literary Virchow's node, where a relatively small and innocuous appearing problem signifies a much more significant and sinister issue; i.e. a small lump under the skin being the harbinger of a lethal metastatic malignancy. I know of several

Roger W. Byard

roger.byard@sa.gov.au

1 Forensic Science SA and School of Medicine, The University of Adelaide, Level 2 Helen Mayo Building North, Frome Road, Adelaide, South Australia 5005, Australia reviewers who first check the references for errors before they even open a manuscript. The reason for this is that to them mistakes in one area could indicate problems elsewhere. In the case of a paper that is bordering on rejection this may be the coup de gras. A question a colleague once put to me was "If the authors are not able to cite the references correctly what might this mean for the rest of the work?" A harsh judgment perhaps but it is one that does have support from experience and this of course is only dealing with the technical side of the references, not whether the content is actually being cited correctly.

It appears to be becoming more common for referencing errors to creep into all manner of work including student assignments and essays. There is not the rigor that was once present to ensure that students and residents are being taught how to reference correctly and to learn the importance of it being done accurately. I was very disappointed to hear a supervisor of an undergraduate university student whose paper had been rejected and criticized for poor referencing, comment that it wasn't her role to check this for the student. I would disagree completely as we are not born with the knowledge of how to write and publish, but must learn it as a craft. My best supervisors were the ones who handed me back drafts dripping with red ink corrections. This was the only way that I learnt and became for me a cornerstone in publishing. A factor that has certainly had an influence recently is the existence of reference management software such as Endnote ${ }^{\circledR}$ or Reference Manager ${ }^{\circledR}$ that are designed to assist with the referencing process. Unfortunately it is a common belief that references once entered into the data bases do not need to be ever checked again.

Common mistakes in referencing are using a style that is not suited to a particular journal, for example Harvard rather than Vancouver, or alphabetical rather than chronological. Inconsistencies in journal names are also very common, so Forensic Science Medicine and Pathology may be randomly italicized or bolded. In sequential references it may appear as Forensic Science Medicine and Pathology, Forens Sci Med Pathol, Forensic Sci Med \& Pathology, and so on. Authors' 
names may be in full or have the initials before or after. Full stops are often randomly distributed like bullets at a small arms range, dois/web addresses may be used for papers that have been in print for years and reference numbers in the text may be superscripted rather than in brackets. Of course, a style not appropriate to the journal often alerts an editor to the fact that the paper has already been submitted elsewhere and rejected.

Getting the references technically wrong is also often a great burden on editors who have to check the style and then send the paper back to the authors for corrections. Very frustratingly, it is not rare to have a manuscript returned with only some of the references corrected and not others. The record for our journal is of four re-submissions before it was done correctly.

To determine how frequently authors submit papers with technically incorrect referencing to Forensic Science Medicine and Pathology, 100 consecutive Original Article, Review and Case Report submissions were reviewed. The total number of papers with referencing errors was 36, indicating that in more than one third of submissions authors had either not followed or had ignored the Instructions for Authors. Of concern, this figure is probably higher as manuscripts that had been rejected were not included in the analysis. This of course is not unique to Forensic Science Medicine and Pathology as anyone who reviews regularly for scientific journals knows.

Finally, Dr. Homes felt that the only logical conclusion that could be drawn from the myriad of idiosyncratic submissions to journals was that the primary aim of most authors was not to get their papers published. His tips on how to get rejected included:
1. Not discussing the manuscript with co-authors (they may improve it);

2. Not showing the head of department (unless he/she is jetlagged);

3. Not reading the instructions to authors

4. Ignoring the requirement for a signed copyright transfer;

5. Enclosing an explanation to the editor as to why you adopted your own formatting, thus drawing attention to major deficiencies in the paper;

6. Not advising the journal of any change of address [1].

More than 30 years after it was written, it remains a truly inspired and insightful paper that helps authors and editors feel that they are not alone in the confused world of publishing. However, my plea to authors is to please check your references carefully. Always follow the Instructions to Authors and also go over your reference list for mistakes if you have used reference management software. The reward for you will be that reviewers and editors will be impressed with your diligence and the processing time for your submission may be considerably shortened.

\section{References}

1. Home PD. Techniques for ensuring that your next paper is quite unsuitable for publication. J R Coll Phys Lond. 1988;22:48-50.

2. Byard RW, Tsokos M. Research, publishing, and forensic pathology. Forensic Sci Med Pathol. 2005;1:237-8.

3. Byard RW. Forensic text books - how to publish and perish, all at the same time. Forensic Sci Med Pathol. 2015;11:111-2.

Publisher's note Springer Nature remains neutral with regard to jurisdictional claims in published maps and institutional affiliations. 